\author{
Pathophysiology \\ of Haemostasis \\ and Thrombosis
}

\title{
Nitric Oxide-cGMP and Prostacyclin-cAMP Pathways in Patients with Type II Diabetes and Different Types of Retinopathy
}

\author{
J.P. De La Cruz ${ }^{a}$ A. Moreno ${ }^{b}$ A. Guerrero ${ }^{a}$ G. Ortega ${ }^{b}$ \\ J.A. González-Correa ${ }^{a}$ F. Sánchez de la Cuesta ${ }^{a}$ \\ aDepartment of Pharmacology and Therapeutics, School of Medicine, University of Málaga, \\ bDepartment of Ophthalmology, Virgen de la Victoria University Hospital, Málaga, Spain
}

\section{Key Words}

Nitric oxide · Platelets · Prostacyclin - Endothelial

dysfunction $\cdot$ Diabetic retinopathy

\begin{abstract}
The aim of this study was to investigate two factors of endothelial dysfunction and their platelet second messengers in patients with type II diabetes and different types of retinopathy. We compared 20 healthy volunteers and 117 patients with type II diabetes (34 with no signs of diabetic retinopathy, 26 with background diabetic retinopathy, 29 with ischemic-proliferative diabetic retinopathy and 28 with edematous diabetic retinopathy). The following parameters were recorded: platelet aggregometry, nitrites, 6-keto-prostaglandin- $F_{1 \alpha}$ and intraplatelet CAMP and CGMP. Platelet aggregation was greater in patients with diabetic retinopathy. The concentration of ADP that produced $50 \%$ maximum intensity of aggregation was $1.81 \mu \mathrm{M}$ in patients without diabetic retinopathy, $0.92 \mu \mathrm{M}$ in patients with background diabetic retinopathy, $0.85 \mu \mathrm{M}$ in patients with ischemic-proliferative diabetic retinopathy and $0.44 \mu \mathrm{M}$ in patients with edematous diabetic retinopathy. The platelets in these patients were more resistant to inhibition by SIN-1 (concentrations of SIN-1 that produced $50 \%$ inhibition of maximum intensity of collagen-induced aggregation in the four
\end{abstract}

patient groups: 18.1, 13.6, 16.2 and $33.2 \mu \mathrm{M}$, respectively). Nitrite concentration in patients with ischemic-proliferative diabetic retinopathy was one sixth of the value in healthy controls, but there was no significant difference between the control group and patients with edematous diabetic retinopathy. In the latter group, neutrophils increased nitrite production by $68.7 \pm 3 \%$, whereas in patients with ischemic-proliferative diabetic retinopathy, this increase was $18.7 \pm 2.0 \%$. We conclude that nitric oxide production is higher in patients with type II diabetes and edematous retinopathy than in those with ischemic-proliferative retinopathy. This finding, together with the possibly greater production of free radicals, may explain the greater impairment of platelet function in the former patients.

Copyright $\odot 2002$ S. Karger AG, Basel

\section{Introduction}

After 20-25 years of suffering from diabetes, more than $80 \%$ of patients have some type of retinal lesion, and these patients are 20 times more likely to become blind than members of the general population [1-3].

A prolonged increase in levels of blood glucose is recognized as one of the main causes of the appearance and evolution of diabetic microangiopathy, of which retinopa-

\begin{tabular}{ll}
\hline KARGER & ( ) 2002 S. Karger AG, Basel \\
Fax +4161306 1234 $34-8832 / 02 / 0321-0025 \$ 18.50 / 0$ \\
$\begin{array}{l}\text { E-Mail karger@karger.ch } \\
\text { www.karger.com }\end{array}$ & $\begin{array}{l}\text { Accessible online at: } \\
\text { www.karger.com/journals/pht }\end{array}$
\end{tabular}

J.P. De La Cruz

Department of Pharmacology and Therapeutics, School of Medicine

University of Málaga, Campus de Teatinos s/n

E-29071 Málaga (Spain)

Tel.+34952 131567, Fax +34952 131568,E-Mail jpcruz@uma.es 
Table 1. Mean characteristics of the healthy volunteers and patients with type II diabetes

\begin{tabular}{|c|c|c|c|c|c|}
\hline & Group 1 & Group 2 & Group 3 & Group 4 & Group 5 \\
\hline Diabetes & no & yes & yes & yes & yes \\
\hline Number & 20 & 34 & 26 & 29 & 28 \\
\hline Retinopathy & no & no & background & ischemic-proliferative & edematous \\
\hline Age, years & $58.2 \pm 4.5$ & $62.3 \pm 3.6$ & $59.7 \pm 3.1$ & $62.4 \pm 1.3$ & $63.2 \pm 2.4$ \\
\hline Gender $(\mathrm{F} / \mathrm{M})$ & $11 / 9$ & $14 / 14$ & $11 / 15$ & $15 / 14$ & $13 / 15$ \\
\hline Duration of diabetes, years & 0 & $12.1 \pm 2.2$ & $11.8 \pm 1.9$ & $10.9 \pm 2.1$ & $12.2 \pm 2.8$ \\
\hline $\mathrm{HbA}_{1 \mathrm{c}}, \%$ & $3.8 \pm 0.1$ & $5.7 \pm 0.8$ & $6.4 \pm 0.9$ & $7.8 \pm 0.9$ & $8.1 \pm 1.1$ \\
\hline Systolic blood pressure, $\mathrm{mm} \mathrm{Hg}$ & $131 \pm 12$ & $139 \pm 15$ & $135 \pm 15$ & $137 \pm 16$ & $133 \pm 18$ \\
\hline Diastolic blood pressure, $\mathrm{mm} \mathrm{Hg}$ & $65 \pm 5.5$ & $68 \pm 4.2$ & $70 \pm 6.4$ & $68 \pm 5.5$ & $75 \pm 6.0$ \\
\hline Microalbuminuria, mg/dl & $0 \pm 0$ & $0 \pm 0$ & $0 \pm 0$ & $2.2 \pm 0.9$ & $6.5 \pm 1.2$ \\
\hline
\end{tabular}

thy is one type [4]. Sustained hyperglycemia leads to a series of interrelated alterations that can cause evident endothelial dysfunction - which in turn can cause vascular lesions in the retina of patients with diabetes and retinopathy [5].

One of the main consequences of endothelial dysfunction is a deficit in nitric oxide (NO) and prostacyclin, substances with vasodilating and platelet-inhibiting functions $[6,7]$. In this connection, platelet hyperactivity has been widely documented in patients with diabetes mellitus, and this hyperactivity is greater in patients with microangiopathy [8-12].

In previous studies [13,14], we showed that platelet alterations in patients with type I diabetes mellitus differed depending on whether their retinopathy was predominantly ischemic or edematous. The aim of the present study was to measure prostacyclin and NO production after activation of these pathways by different substances, i.e. $L$-arginine for NO and a calcium ionophore for prostacyclin, and the activation of their platelet second messengers cAMP and cGMP by prostaglandin $\mathrm{E}_{1}$ and SIN-1, respectively, in patients with type II diabetes mellitus with different types of retinopathy.

Endothelial cells are the best source to exactly determine prostacyclin and NO, but this is obviously difficult in humans. For that reason, we studied NO production in neutrophils and prostacyclin in mononuclear leukocytes as peripheral blood cells that produce these substances.

\section{Patients and Methods}

\section{Patient Selection}

The participants in this study were 20 healthy volunteers and 117 patients with diabetes diagnosed as type II (non-insulin-dependent diabetes mellitus; NIDDM). We excluded patients with other types of vasculopathy (macro- or microangiopathy). Except for oral glucose-lowering drugs, none of the subjects took any medication at the time of the study or during the 15 days before inclusion. All participants were given the same recommendations regarding dietary measures, exercise and lifestyle. All participants gave their informed consent in writing after receiving information about the aims of the study, and the procedure was approved by the Ethics Committee of the Virgen de la Victoria University Hospital in Málaga, Spain.

All patients and healthy volunteers underwent a complete ophthalmologic examination, which included evaluation of the visual field, intraocular pressure, lens and fluorescein angiography (FAG). On the basis of the FAG results, the participants were divided into five groups. Group $1(n=20)$ comprised persons without diabetes or signs of retinopathy. Group $2(n=34)$ consisted of patients with NIDDM with no signs of retinopathy. Group $3(n=26)$ contained patients with NIDDM and background retinopathy, defined as the presence on FAG of small microaneurysms, small, rounded parietal hemorrhages, small, rounded areas of infiltration or any combination of the three, with no evidence of the formation of hard exudates and no more than 6 leaks identified with fluorescein. The patients in group $4(n=29)$ had NIDDM and predominantly ischemic-proliferative retinopathy, defined as the presence of new vessel formation (intraretinal, preretinal, papillary or vitreous), with leaks in the new vessels in the early phase of FAG. Group $5(n=28)$ contained patients with NIDDM and predominantly edematous retinopathy, defined as the presence of abundant, confluent infiltrates that formed plaques and diffuse retinal edema (more than 6 leaks). Table 1 summarizes the main characteristics of the participants in each group.

At the end of the study, a blood sample was obtained from each participant between 8.00 and $9.00 \mathrm{~h}$, before the subject had anything to eat or drink, and before the patients had injected their daily insulin dose.

Glycosylated hemoglobin $\left(\mathrm{HbA}_{1 \mathrm{c}}\right)$, duration of diabetes, daily insulin dose and other findings of interest were recorded from the patient's clinical record. For each patient, $\mathrm{HbA}_{1 \mathrm{c}}$ was measured 2 or 3 times per year, and the value used in this study was the mean of the three most recent measurements.

\section{Laboratory Procedures}

All reagents were from Sigma Chemical Co. (St. Louis, Mo., USA) unless otherwise stated. Blood samples were collected with 3.8\% sodium citrate as the anticoagulant at a proportion of 1:10. Each 
Table 2. $\mathrm{EC}_{50}$ values of the inducers of platelet aggregation

\begin{tabular}{llllll}
\hline & $\begin{array}{l}\text { ND } \\
(\mathrm{n}=20)\end{array}$ & $\begin{array}{l}\text { DWR } \\
(\mathrm{n}=34)\end{array}$ & $\begin{array}{l}\text { DBR } \\
(\mathrm{n}=26)\end{array}$ & $\begin{array}{l}\text { DIPR } \\
(\mathrm{n}=29)\end{array}$ & $\begin{array}{l}\text { DER } \\
(\mathrm{n}=28)\end{array}$ \\
\hline ADP in PRP, $\mu M$ & $2.11 \pm 0.29$ & $1.99 \pm 0.21$ & $1.82 \pm 0.20$ & $1.94 \pm 0.25$ & $1.90 \pm 0.26$ \\
ADP in WB, $\mu M$ & $2.15 \pm 0.17$ & $1.81 \pm 0.07$ & $0.92 \pm 0.06^{*}$ & $0.85 \pm 0.04^{*}$ & $0.44 \pm 0.06^{*}$ \\
Collagen in PRP, $\mu \mathrm{g} / \mathrm{ml}$ & $0.71 \pm 0.08$ & $0.77 \pm 0.07$ & $0.81 \pm 0.09$ & $0.77 \pm 0.08$ & $0.41 \pm 0.06^{*}$ \\
Collagen in WB, $\mu \mathrm{g} / \mathrm{ml}$ & $0.48 \pm 0.05$ & $0.46 \pm 0.05$ & $0.40 \pm 0.03$ & $0.34 \pm 0.03$ & $0.17 \pm 0.02^{*}$ \\
\hline
\end{tabular}

$* \mathrm{p}<0.05$ in comparison to all the other groups. $\mathrm{ND}=$ Volunteers without diabetes; $\mathrm{DWR}=$ patients with diabetes without retinopathy; DBR = patients with diabetes and background retinopathy; DIPR = patients with diabetes and ischemic-proliferative retinopathy; DER = patients with diabetes and edematous retinopathy; $\mathrm{WB}=$ whole blood.

sample was divided into aliquots for analyses of whole blood, platelet-rich plasma (PRP), mononuclear leukocytes and neutrophils. PRP was obtained by centrifuging whole blood at $180 \mathrm{~g}$ for $10 \mathrm{~min}$ at $20^{\circ} \mathrm{C}$. Mononuclear leukocytes and neutrophils were obtained on a Ficoll density gradient (Histopaque 1077 and 1119).

\section{Platelet Aggregation}

The maximum intensity of platelet aggregation induced by ADP or collagen (Menarini Diagnóstica SA, Barcelona, Spain) in whole blood or PRP was measured using an electrical impedance method [15] (Chrono-Log 530S aggregometer, Chrono-Log Corporation, Haverton, Pa., USA). The maximum intensity of aggregation was recorded as the maximum change in impedance $10 \mathrm{~min}$ after the inducing agent was added. The concentration of the inducers of platelet aggregation that produced $50 \%$ maximum intensity of aggregation was defined as $\mathrm{EC}_{50}$. In some experiments with PRP, the samples were incubated with different concentrations of prostaglandin $E_{1}$ (adenyl cyclase stimulant) or SIN-1 (guanyl cyclase stimulant), and aggregation was induced by adding $1 \mu \mathrm{g} / \mathrm{ml}$ collagen. The concentration of prostaglandin $\mathrm{E}_{1}$ and SIN- 1 that produced $50 \%$ inhibition of the maximum intensity of collagen-induced aggregation was defined as $\mathrm{IC}_{50}$.

\section{Nitrites and Nitrates}

$\mathrm{NO}$ is rapidly converted to $\mathrm{NO}_{2}^{-}$and $\mathrm{NO}_{3}^{-}(\mathrm{NOx})$ in an oxygenated aqueous solution such as human plasma. Samples were filtered through Ultrafree-MC microcentrifuge filters (Millipore, Gif-SurYvette, France) to remove the hemoglobin from cell lysis. A commercial kit (Cayman Chemical, Ann Arbor, Mich., USA) was used to measure NOx concentration. Concentrations of NOx were measured in plasma and in the supernatant of neutrophils stimulated for 30 min with $100 \mu M L$-arginine.

\section{Prostacyclin Concentration}

The concentration of prostacyclin was quantified by determining the concentration of 6-keto-prostaglandin- $\mathrm{F}_{1 \alpha}$ in samples of mononuclear leukocytes and cell-free plasma. Calcium ionophore A2187 $(1 \mu M)$ was added, and the mixture was incubated for $5 \mathrm{~min}$ at $37^{\circ} \mathrm{C}$ and then centrifuged at $10,000 \mathrm{~g}$ for $3 \mathrm{~min}$. The supernatant was frozen at $-80^{\circ} \mathrm{C}$ until analysis. The concentration of 6-keto-prostaglandin- $\mathrm{F}_{1 \alpha}$ was measured by enzyme immunoassay (Amersham International plc, Little Chalfont, Buckinghamshire, UK).

\section{Platelet cAMP}

Platelets from PRP were washed in a medium composed of $5.6 \mathrm{~g} / 1$ $\mathrm{NaCl}, 0.7 \mathrm{~g} / 1 \mathrm{NaH}_{2} \mathrm{PO}_{4}, 0.5 \mathrm{~g} / 1 \mathrm{KH}_{2} \mathrm{PO}_{4}, 0.9 \mathrm{~g} / \mathrm{l}$ glucose, $0.05 \mathrm{~g} / \mathrm{l}$ apyrase and $50 \mathrm{n} M$ prostaglandin $\mathrm{E}_{1}$. The sample was centrifuged at $1,000 \mathrm{~g}$ for $15 \mathrm{~min}$ at $4^{\circ} \mathrm{C}$, and the resulting pellet was resuspended in a solution consisting of $7.7 \mathrm{~g} / 1 \mathrm{NaCl}, 0.6 \mathrm{~g} / 1 \mathrm{NaH}_{2} \mathrm{PO}_{4}, 1 \mathrm{~g} / \mathrm{l}$ $\mathrm{NaHCO}_{3}, 0.3 \mathrm{~g} / \mathrm{C} \mathrm{CaCl}_{2}, 0.2 \mathrm{~g} / 1 \mathrm{MgCl}_{2}, 1.2 \mathrm{~g} / \mathrm{l}$ HEPES, $0.9 \mathrm{~g} / \mathrm{l}$ glucose, $0.05 \mathrm{~g} / \mathrm{l}$ apyrase and $0.5 \mathrm{~g} / \mathrm{l}$ bovine albumin. The number of platelets was adjusted to $2.5 \times 10^{11}$ cells/l, and the sample was divided into aliquots to which we added $10 \mu M$ isobutylmethylxanthine and $1 \mu M$ prostaglandin $\mathrm{E}_{1}$. After incubation for $5 \mathrm{~min}$ at $37^{\circ} \mathrm{C}$, the process was stopped by adding $1 \mathrm{~N} \mathrm{HCl}$. The sample was centrifuged at $10,000 \mathrm{~g}$ for $3 \mathrm{~min}$ and the resulting supernatant was neutralized with $\mathrm{NaOH}$. The production of cAMP was measured by enzyme immunoassay (Amersham International).

\section{Intraplatelet c $G M P$}

Samples were prepared as described above for cAMP, except that $100 \mu M$ zaprinast was used instead of isobutylmethylxanthine, and $10 \mu M$ SIN-1 was used instead of prostaglandin $\mathrm{E}_{1}$. The production of cGMP was measured by enzyme immunoassay (Amersham International).

\section{Statistical Analysis}

The results were expressed as the mean \pm SEM. Differences between groups were detected with one-way analysis of variance followed by testing for the least significant difference. Simple linear correlations were also calculated. Differences were considered significant at $\mathrm{p}<0.05$. The SPSS program (version 10.0 for Windows, SPSS Co., Chicago, Ill., USA) was used for all statistical analyses.

\section{Results}

Platelet aggregation increased in a concentration-dependent way after stimulation with collagen or ADP, both in whole blood and PRP (data not shown). Table 2 shows the $\mathrm{EC}_{50}$ values for inducers of platelet aggregation (ADP and collagen). The differences between groups were significant only after induction with collagen in PRP from patients with diabetes and edematous retinopathy. The 

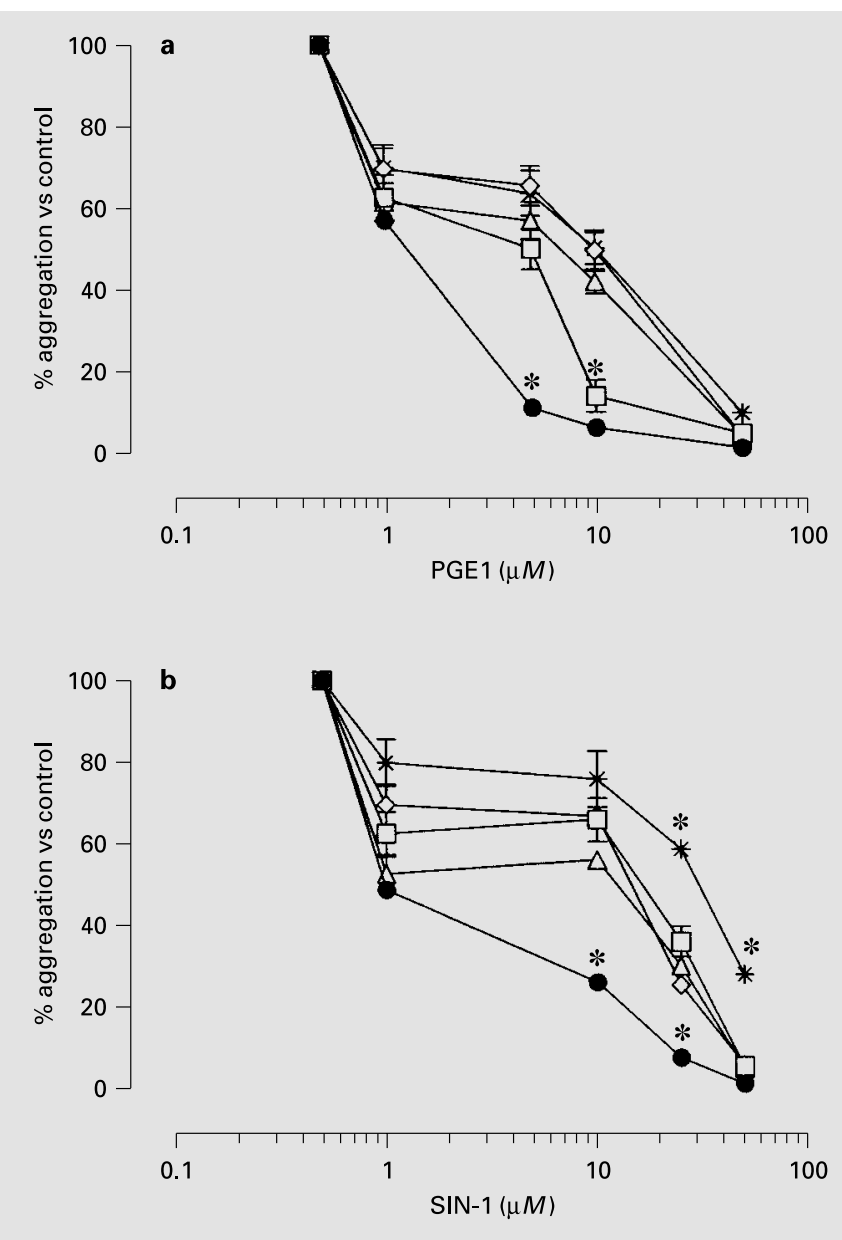

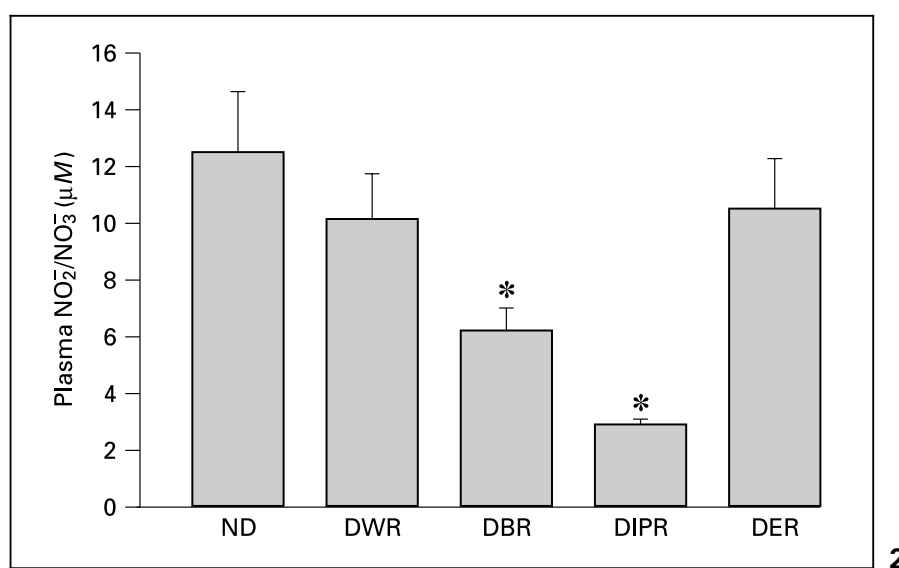

Fig. 1. Inhibition of platelet aggregation in PRP induced with $1 \mu \mathrm{g} /$ $\mathrm{ml}$ collagen, after incubation with increasing concentrations of prostaglandin $\mathrm{E}_{1}\left(\mathrm{PGE}_{1}\right)(\mathbf{a})$ or SIN-1 (b). $\bullet=$ Volunteers without diabetes $(\mathrm{n}=20) ; \square=$ patients with diabetes but without retinopathy $(\mathrm{n}=34) ; \triangle=$ patients with diabetes and background retinopathy $(\mathrm{n}=26) ; \diamond=$ patients with diabetes and ischemic-proliferative retinopathy $(\mathrm{n}=29) ; *=$ patients with diabetes and edematous retinopathy $(\mathrm{n}=28){ }^{*} \mathrm{p}<0.05$ in comparison to all other groups.

Fig. 2. Plasma concentrations of $\mathrm{NO}_{2}^{-} / \mathrm{NO}_{3}^{-}$. $\mathrm{ND}=$ Volunteers without diabetes $(\mathrm{n}=20)$; DWR $=$ patients with diabetes but without retinopathy $(\mathrm{n}=34)$; $\mathrm{DBR}=$ patients with diabetes and background retinopathy $(\mathrm{n}=26)$; DIPR $=$ patients with diabetes and ischemicproliferative retinopathy $(n=29)$; DER $=$ patients with diabetes and edematous retinopathy $(\mathrm{n}=28) .{ }^{*} \mathrm{p}<0.05$ in comparison to all other groups.

Table 3. $\mathrm{IC}_{50}$ values of prostaglandin $\mathrm{E}_{1}$ and SIN-1 in PRP

\begin{tabular}{llllll}
\hline & $\begin{array}{l}\text { ND } \\
(\mathrm{n}=20)\end{array}$ & $\begin{array}{l}\text { DWR } \\
(\mathrm{n}=34)\end{array}$ & $\begin{array}{l}\text { DBR } \\
(\mathrm{n}=26)\end{array}$ & \multicolumn{1}{l}{$\begin{array}{l}\text { DIPR } \\
(\mathrm{n}=29)\end{array}$} & \multicolumn{1}{l}{$\begin{array}{l}\text { DER } \\
(\mathrm{n}=28)\end{array}$} \\
\hline $\mathrm{PGE}_{1}, \mu M$ & $1.63 \pm 1.51^{*}$ & $5.01 \pm 0.41$ & $7.35 \pm 0.55$ & $9.91 \pm 0.85$ & $10.30 \pm 1.18$ \\
$\mathrm{SIN}-1, \mu M$ & $1.08 \pm 0.06^{*}$ & $18.10 \pm 2.02$ & $13.60 \pm 1.59$ & $16.22 \pm 1.93$ & $33.26 \pm 2.28^{*}$ \\
\hline
\end{tabular}

$* \mathrm{p}<0.05$ in comparison to all the other groups. ND = Volunteers without diabetes; DWR $=$ patients with diabetes without retinopathy; DBR = patients with diabetes and background retinopathy; DIPR = patients with diabetes and ischemic-proliferative retinopathy; $\mathrm{DER}=$ patients with diabetes and edematous retinopathy; $\mathrm{PGE}_{1}=$ prostaglandin $\mathrm{E}_{1}$.

$\mathrm{EC}_{50}$ for $\mathrm{ADP}$ was significantly lower in whole blood from patients with diabetes and retinopathy than in that from the patients without retinopathy and the healthy group. The $\mathrm{EC}_{50}$ for collagen was significantly lower in whole blood from patients with diabetes and edematous retinopathy than in that from the other groups.
Prostaglandin $\mathrm{E}_{1}$ inhibited platelet aggregation induced by collagen in a concentration-dependent way (fig. 1). Inhibition was greater in volunteers without diabetes than in patients with the disease, and among the latter, inhibition was lowest in patients with edematous retinopathy. SIN-1 also inhibited aggregation induced by col- 


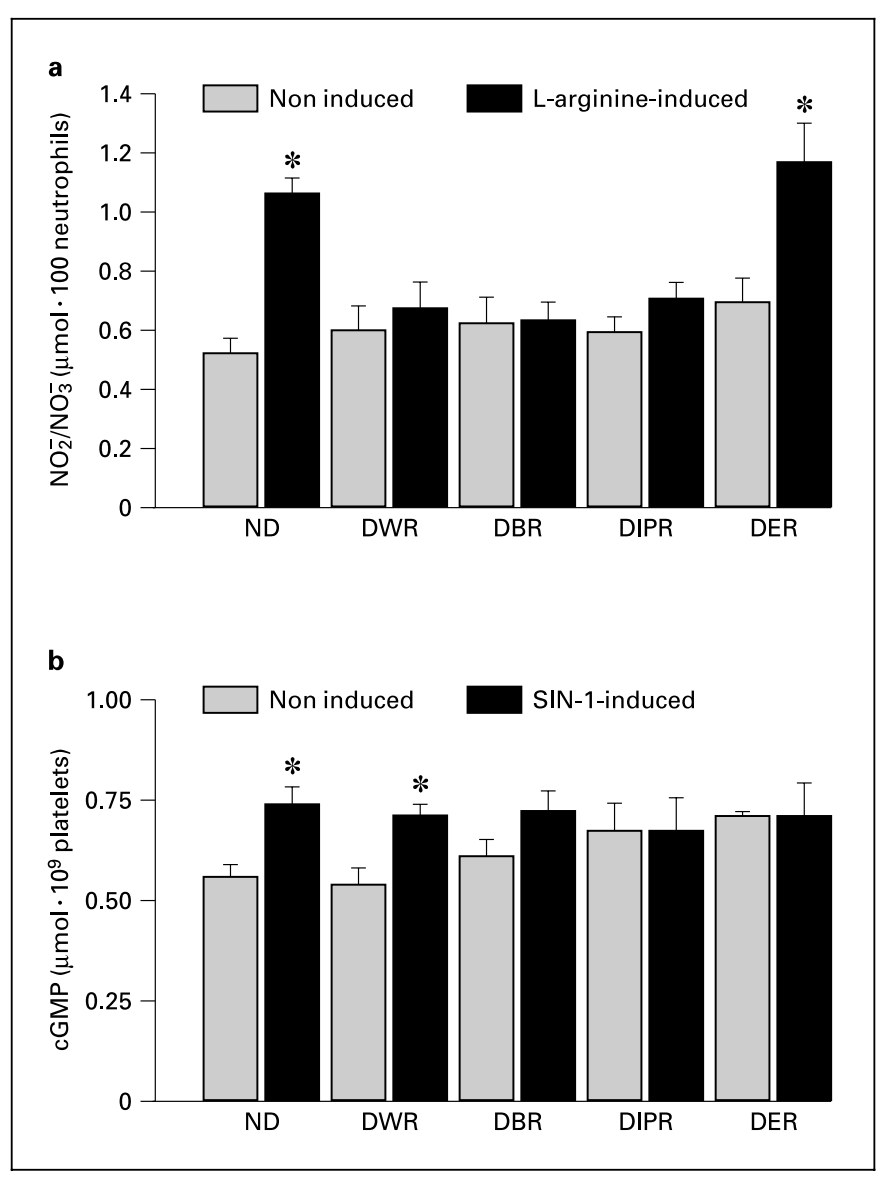

Fig. 3. $\mathbf{a} \mathrm{NO}_{2}^{-} / \mathrm{NO}_{3}^{-}$production in neutrophils under basal conditions (white bars) and after stimulation with $100 \mu M L$-arginine (hatched bars). b Intraplatelet concentrations of cGMP under basal conditions (white bars) and after stimulation with $10 \mu M$ SIN-1 (hatched bars). $\mathrm{ND}=$ Volunteers without diabetes $(\mathrm{n}=20)$; DWR $=$ patients with diabetes but without retinopathy $(\mathrm{n}=34)$; $\mathrm{DBR}=$ patients with diabetes and background retinopathy $(n=26)$; DIPR $=$ patients with diabetes and ischemic-proliferative retinopathy $(n=29)$; DER $=$ patients with diabetes and edematous retinopathy $(n=28) .{ }^{*} \mathrm{p}<0.05$ in comparison to all other groups.

lagen in a concentration-dependent way. Resistance to inhibition by SIN-1 was greatest in patients with edematous retinopathy. Table 3 shows the $\mathrm{IC}_{50}$ values for prostaglandin $\mathrm{E}_{1}$ and SIN-1.

Plasma concentrations of NOx are illustrated in figure 2. In patients with diabetes and background or ischemic-proliferative retinopathy, plasma NOx concentrations were lower than in the other two groups of patients. The concentration of NOx in patients with diabetes but no retinopathy or edematous retinopathy did not differ significantly from that in healthy control participants.

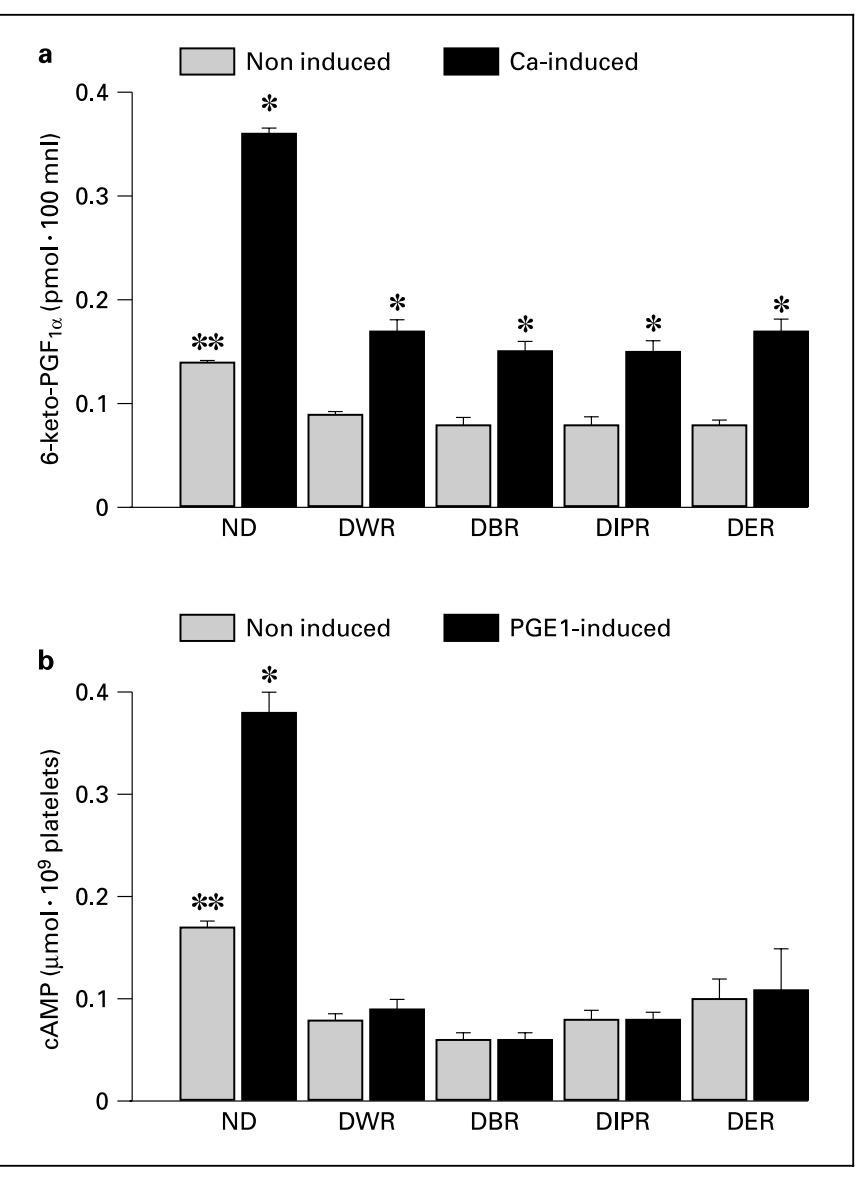

Fig. 4. a 6-Keto-prostaglandin- $\mathrm{F}_{1 \alpha}\left(6-\right.$ keto- $\left.-\mathrm{PGF}_{1 \alpha}\right)$ production in mononuclear leukocytes under basal conditions (white bars) and after stimulation with $1 \mu M$ calcium ionophore A23187 (hatched bars). b Intraplatelet concentrations of cGMP under basal conditions (white bars) and after stimulation with $10 \mu M$ prostaglandin $\mathrm{E}_{1}$ (PGE1) (hatched bars). ND = Volunteers without diabetes $(\mathrm{n}=20)$; DWR = patients with diabetes but without retinopathy $(n=34)$; $\mathrm{DBR}=$ patients with diabetes and background retinopathy $(\mathrm{n}=26)$; DIPR $=$ patients with diabetes and ischemic-proliferative retinopathy $(\mathrm{n}=29)$; DER = patients with diabetes and edematous retinopathy $(\mathrm{n}=28) .{ }^{*} \mathrm{p}<0.05$ in comparison to noninduced samples; $* * \mathrm{p}<$ 0.05 in comparison to all other groups of diabetic patients.

NO production by neutrophils stimulated with $L$-arginine (fig. 3a) was significantly greater in healthy volunteers than in patients with diabetes and edematous retinopathy. Platelet concentrations of cGMP (fig. 3b) were similar in all five groups, although cGMP production after induction with SIN-1 showed no significant change in platelet samples from patients with ischemic-proliferative or edematous retinopathy.

Plasma levels of 6-keto-prostaglandin- $\mathrm{F}_{1 \alpha}$ were significantly higher in healthy people $(18.25 \pm 2.05 \mathrm{nmol} / \mathrm{l})$ than in patients with diabetes; the values in the patient 
groups were $15.33 \pm 2.35 \mathrm{nmol} / 1$ in diabetic patients without retinopathy $(\mathrm{p}<0.05), 13.49 \pm 1.95 \mathrm{nmol} / \mathrm{l}$ in patients with diabetes and background retinopathy $(\mathrm{p}<$ $0.05), 4.51 \pm 0.66 \mathrm{nmol} / \mathrm{l}$ in patients with diabetes and ischemic-proliferative retinopathy $(\mathrm{p}<0.001)$ and $1.23 \pm$ $0.21 \mathrm{nmol} / \mathrm{l}$ in patients with diabetes and edematous retinopathy $(\mathrm{p}<0.001)$.

Leukocyte production of 6-keto-prostaglandin- $\mathrm{F}_{1 \alpha}$ increased significantly after stimulation with calcium ionophore (fig. 4a) in all groups, although leukocytes from healthy volunteers showed the largest increase. Intraplatelet concentrations of cAMP (fig. 4b) were significantly lower in patients with diabetes than in healthy controls. In contrast with the results in the control group, stimulation with prostaglandin $E_{1}$ led to no significant increase in cAMP levels in any of the patients with diabetes.

\section{Discussion}

Our study shows that platelet alterations, as assessed by prostacyclin and NO levels and the activation of their platelet second messengers, in patients with NIDDM diabetes differ depending on the type of retinopathy these patients have.

Our aggregometric findings are similar to those of most authors who have studied this parameter in patients with diabetes, in whom platelet aggregation is more sensitive to stimulation by habitual inducers than in healthy persons [8-12]. This result is compatible with earlier findings by our group in patients with type I diabetes mellitus [13, 14], in whom aggregation was also greater than in healthy controls, and among whom the difference was especially striking for patients with edematous retinopathy. Our present findings show that platelet reactivity is also enhanced in patients with type II diabetes and edematous retinopathy.

Experiments that have investigated endogenous antiaggregant substances have showed that platelets from patients with diabetes are less sensitive to inhibition by these antiaggregants than those from healthy volunteers. These results are similar to earlier findings reported with adenosine or $L$-arginine $[16,17]$. Platelet inhibition via the adenyl cyclase pathway (incubation with prostaglan$\operatorname{din} E_{1}$ ) did not differ between the groups of patients with retinopathy, but was lower in patients with no retinopathy. This indicates that this pathway is more severely altered when microangiopathic complications appear. However, when we tested the guanyl cyclase pathway of platelet inhibition (incubation with SIN-1), we found a greater degree of resistance to inhibition in patients with edematous retinopathy in comparison to other retinopathies.

Plasma concentrations of NOx, together with the greater platelet activity and lower sensitivity to inhibition by SIN-1, support the existence of a platelet imbalance that might account for the appearance of ischemia [18]. In this connection, it has been shown that nitrite levels in patients with diabetes but without vascular complications are similar to those in the healthy population, whereas in patients with vasculopathies, plasma nitrite levels are lowered [19]. Decreased platelet [20, 21] and vascular constitutive NO synthase activity [22] have been suggested as the causes of reduced NO production in patients with diabetes. Our findings suggest that this reduction is also the result of decreased NO production in neutrophils.

Nonetheless, patients with diabetes and edematous retinopathy stood out because of the absence of any reduction in plasma NOx levels. In theory, we would have assumed that because of the increase in NO, platelet inhibition would be greater, but in fact the data showed that inhibition was less intense in this subgroup of patients. To explain this apparent paradox, we analyzed NO production by neutrophils and the activity of cGMP, its second messenger in platelets. In patients with diabetes, NO synthase activity was lower, as shown by the lower level of NOx in the supernatant after incubation with $L$-arginine. This result is compatible with earlier reports of a lower activity of constitutive NO synthase in patients with diabetes [20, 21]. However, the pattern of NOx production differed in patients with edematous retinopathy; basal NOx production was not significantly lower than in healthy volunteers, and induction with $L$-arginine led to higher NOx levels than in other subgroups of retinopathy.

Intraplatelet cGMP formation was clearly diminished in patients with any type of retinopathy [23]. This may explain the greater platelet activity and blunted sensitivity to inhibition by SIN-1. Hence, the defect in the NOcGMP axis appears to occur in NO formation. The increased production of NOx in patients with edematous retinopathy might be explainable by the formation of peroxynitrites; in patients with diabetes, the formation of free radicals is greater and the antioxidant defense capacity lower than in healthy persons [24, 25]. In addition, superoxide anions react with NO to form peroxynitrite radicals [26], which are highly oxidizing and markedly increase platelet aggregation [27, 28]. On the basis of this explanation, it might be suspected that in patients with 
type II diabetes and edematous retinopathy, more free radicals would form and react with $\mathrm{NO}$ to give rise to peroxynitrites, which are detected when NOx production is measured. This would explain the absence of any apparent decrease in plasma NOx in these patients and the increase in NOx production by neutrophils incubated with $L$-arginine. In this connection, the elevated platelet peroxynitrite production in patients with type II diabetes has been shown to result from the 3-fold increase in induced NO synthase activity in comparison to healthy persons [29]. Moreover, Zou and Bachschmid [30] demonstrated that an increase of peroxynitrites leads to prostacyclin inhibition; plasma concentrations of 6-keto-prostaglandin- $F_{1 \alpha}$ were decreased in all diabetic groups, but in patients with edematous retinopathy, this decrease was higher than in other groups. In patients with background and ischemic-proliferative retinopathy, the endothelial dysfunction could explain this inhibition; according to the results of Zou and Bachschmid [30], in patients with edematous retinopathy, the lowest plasma levels of 6keto-prostaglandin- $\mathrm{F}_{1 \alpha}$ could be a consequence of the formation of peroxynitrites. However, to confirm this hypothesis, further research is needed to show that more free radicals and peroxynitrites are formed in these patients than in patients with diabetes and other types of retinopathy.

The prostacyclin-cAMP axis is also altered in patients with diabetes; the production of the prostanoid is lower, and sensitivity to platelet adenyl cyclase is diminished.
These alterations are further evidence of the platelet alterations in patients with diabetes; however, we found no differences between patients with different types of retinopathy. Experimental studies have shown a relationship between the vascular production of prostacyclin and retinal vascularization in rats with streptozotocin-induced diabetes [31], and changes in prostacyclin synthesis modify the intensity of retinal ischemia in this model [32-34]. However, in animals made diabetic, only ischemic retinopathy has been reproduced, but not edematous retinopathy.

In conclusion, there is a clear imbalance between platelet activity and the function of endogenous NO-cGMP and prostacyclin-cAMP pathways in patients with type II diabetes mellitus, and this imbalance is especially evident in patients with edematous retinopathy. The differences we found between patients with different types of retinopathy suggest new approaches to research on the mechanisms that favor or impede the appearance of each type of retinopathy and raise the possibility that different treatments may be appropriate for each group. However, further studies will be needed to learn more about these mechanisms in patients with different types of retinopathy.

\section{Acknowledgments}

We thank Antonio Pino Blanes for his excellent technical help and K. Shashok for translating the manuscript into English.

\section{References}

1 Brailsford SC, Davies R, Canning C, Roderick PJ: Evaluating policies for the early detection of retinopathy in patients with non-insulin dependent diabetes. Health Care Manag Sci 1998;1:115-124.

2 Klein R, Palta M, Allen C, Shen G, Han DP, D'Alessio DJ: Incidence of retinopathy and associated risk factors from time of diagnosis of insulin-dependent diabetes. Arch Ophthalmol 1997; 115:351-356.

3 Reuterving CO, Kratholm J, Wachtmeister L: Ophthalmic health care in diabetes mellitus: A cross-sectional study in northern Sweden. Ophthalmic Epidemiol 1999;6:267-278.

4 Retinopathy and nephropathy in patients with type 1 diabetes four years after a trial of intensive therapy. The Diabetes Control and Complications Trial/Epidemiology of Diabetes Interventions and Complications Research Group. N Engl J Med 2000;342:381-389.
5 De Vriese AS, Verbeuren TJ, Van de Voorde J, Lameire NH, Vanhoutte PM: Endothelial dysfunction in diabetes. Br J Pharmacol 2000;130: 963-974.

6 Moncada S, Vane JR: Unstable metabolites of arachidonic acid and their role in haemostasis and thrombosis. Br Med Bull 1978;34:129135.

7 Radomski MW, Moncada S: The biological and pharmacological role of nitric oxide in platelet function. Adv Exp Med Biol 1993;344: 251-264.

8 Michelson AD, Furman MI: Laboratory markers of platelet activation and their clinical significance. Curr Opin Hematol 1999;6:342348.

9 Knobler H, Savion N, Shenkman B, KotevEmeth S, Varon D: Shear-induced platelet adhesion and aggregation on subendothelium are increased in diabetic patients. Thromb Res 1998;90:181-190.
10 Iwase E, Tawata M, Aida K, Ozaki Y, Kume S, Satoh K, Qi R, Onaya T: A cross-sectional evaluation of spontaneous platelet aggregation in relation to complications in patients with type II diabetes mellitus. Metabolism 1998;47:699_ 705.

11 Roshan B, Tofler GH, Weinrauch LA, Gleason RE, Keough JA, Lipinska I, Lee AT, Delia JA: Improved glycemic control and platelet function abnormalities in diabetic patients with $\mathrm{mi}$ crovascular disease. Metabolism 2000;49:8891.

12 Mazzanti L, Mutus B: Diabetes-induced alterations in platelet metabolism. Clin Biochem 1997;30:509-515.

13 De La Cruz JP, Moreno A, Sintas A, García Campos JM, Sánchez de la Cuesta F: Platelet hyperaggregation in diabetic patients with different types of retinopathy is partially influenced by erythrocytes in whole blood. Diabetes Res 1997;32:51-68. 
14 De La Cruz JP, Moreno A, Guerrero A, Sánchez de la Cuesta F: Antiplatelet effects of prostacyclin and nitric oxide in patients with type I diabetes and ischemic or edematous retinopathy. Platelets 2001;12:210-217.

15 Cardinal DC, Flower RJ: The electronic aggregometer: A novel device for assessing platelet behavior in blood. J Pharmacol Methods 1980; 3:135-158.

16 Gasser JA, Cooper MB, Tan KC, Saggerson ED, Betteridge DJ: Altered cellular signalling and decreased platelet sensitivity to adenosine in insulin-dependent diabetic patients with proliferative retinopathy. Cell Signal 1993;5: 145-153.

17 Mendez JD, Zarzoza E: Inhibition of platelet aggregation by L-arginine and polyamines in alloxan treated rats. Biochem Mol Biol Int 1997;43:311-318.

18 Huszka M, Kaplar M, Rejto L, Tornai I, Palatka K, Laszlo P, Udvardy M: The association of reduced endothelium derived relaxing factorNO production with endothelial damage and increased in vivo platelet activation in patients with diabetes mellitus. Thromb Res 1997;86: 173-180.

19 Ferlito S, Gallina M: Nitrite plasma levels in type 1 and 2 diabetics with and without complications. Panminerva Med 1998;40:304308 .

20 Martina V, Bruno GA, Trucco F, Zumpano E, Tagliabue M, Di Bisceglie C, Pescarmona G: Platelet cNOS activity is reduced in patients with IDDM and NIDDM. Thromb Haemost 1998;79:520-522.
21 Rabini RA, Staffolani R, Fumelli P, Mutus B, Curatola G, Mazzanti L: Decreased nitric oxide synthase activity in platelets from IDDM and NIDDM patients. Diabetologia 1998;41: 101-104.

22 Pitei DL, Watkins PJ, Edmonds ME: NOdependent smooth muscle vasodilation is reduced in NIDDM patients with peripheral sensory neuropathy. Diabet Med 1997;14:284290.

23 Michimata T, Murakami M, Iriuchijima $\mathrm{T}$ : Nitric oxide-dependent soluble guanylate cyclase activity is decreased in platelets from male NIDDM patients. Life Sci 1996;59:14631471.

24 West IC: Radicals and oxidative stress in diabetes. Diabet Med 2000;17:171-180.

25 Bonnefont-Rousselot D, Bastard JP, Jaudon MC, Delattre J: Consequences of the diabetic status on the oxidant/antioxidant balance. Diabetes Metab 2000;26:163-176.

26 Moncada S, Palmer RM, Higgs EA: Nitric oxide: Physiology, pathophysiology, and pharmacology. Pharmacol Rev 1991;43:109-142.

27 Moro MA, Darley-Usmar VM, Goodwin DA, Read NG, Zamora R, Feelisch M, Radomski MW, Moncada S: Paradoxical fate and biological action of peroxynitrite on human platelets. Proc Natl Acad Sci USA 1994;91:6702-6706.
28 Brown AS, Moro MA, Masse JM, Cramer EM, Radomski MW, Darley-Usmar V: Nitric oxidedependent and independent effects on human platelets treated with peroxynitrite. Cardiovasc Res 1998;40:380-388.

29 Tannous M, Rabini RA, Vignini A, Moretti N, Fumelli P, Zielinski B, Mazzanti L, Mutus B: Evidence for iNOS-dependent peroxynitrite production in diabetic platelets. Diabetologia 1999;42:539-544.

30 Zou M-H, Bachschmid M: Hypoxia-reoxygenation triggers coronary vasospasm in isolated bovine coronary arteries via tyrosine nitration of prostacyclin synthase. J Exp Med 1999;190: 135-139.

31 Moreno A, De La Cruz JP, García Campos J, Sánchez de la Cuesta F: Prostacyclin-thromboxane balance and retinal vascular pattern in rats with experimentally induced diabetes. Can J Ophthalmol 1995;30:117-123.

32 De La Cruz JP, Moreno A, Sánchez de la Cuesta F, García Campos J: Effect of antiplatelet drug therapy on the retinal vascular pattern in experimental diabetes. Can J Ophthalmol 1990;25:329-332.

33 De La Cruz JP, Moreno A, Muñoz M, García Campos J, Sánchez de la Cuesta F: Effect of aspirin plus dipyridamole on the retinal vascular pattern in experimental diabetes mellitus. $\mathrm{J}$ Pharmacol Exp Ther 1997;280:454-459.

34 Moreno A, De La Cruz JP, Mérida F, García Campos JM, Sánchez de la Cuesta F: Effects of ditazol on the vascular retinal pattern in experimental diabetes in rats. Haemostasis $1995 ; 25$ : 166-171. 